\title{
INFORME JURÍDICO SOBRE EL CONTROL EXTERNO DEL PRESUPUESTO PARLAMENTARIO (PARLAMENTO VASCO. 12.2.1996)
}

\section{LEGAL REPORT ON THE EXTERNAL CONTROL OF THE PARLIAMENTARY BUDGET (BASQUE PARLIAMENT. 1996.2.12)}

\section{Alberto Figueroa Laraudogoitia}

Ex letrado mayor del Parlamento Vasco

Cómo citar / Nola aipatu: Figueroa Laraudogoitia, A. (2020). Informe jurídico sobre el control externo del presupuesto parlamentario. (Parlamento Vasco 12.02.1996). Legebiltzarreko Aldizkaria - LEGAL - Revista del Parlamento Vasco, (1): 176-189.

https://doi.org/10.47984/legal.2020.008

\section{NOTA INTRODUCTORIA}

I.

Se me ofrece la posibilidad de actualizar el informe jurídico que hace ya casi un cuarto de siglo, el 27 de diciembre de 1995, solicitó la Comisión de Economía, Hacienda y Presupuestos, relativo al control de la ejecución del presupuesto del Parlamento, con especial atención a las fórmulas existentes en el derecho comparado. El informe, que lleva mi firma, expresa la opinión no solo del letrado que lo suscribe, sino el de los Servicios Jurídicos de la Cámara en su conjunto.

Pues bien, a pesar del tiempo transcurrido, podemos concluir afirmando que el informe mantiene, básicamente, su vigencia, y expresa, al menos para quien suscribe esta adenda, una opinión que no ha decaído con el paso del tiempo.

Hay que hacer notar que el informe no tiene como objeto pronunciarse sobre una cuestión de legalidad, es decir, sobre si, de acuerdo con la Constitución, el Estatuto y el resto de las leyes vigentes, la ejecución del presupuesto del Parlamento debe estar sometida al control externo y, en concreto, si ese control lo debe ejercer el Tribunal de Cuentas (el del Estado o el autonómico), sino sobre un tema de oportunidad, esto es, si existen fundamentos y razones para que el Parlamento sacrifique su reconocida autonomía financiera en razón de principios que lo justifiquen, como puede ser el de trasparencia. 
Como se indica, las conclusiones del informe exponen la situación existente, todavía, a día de hoy. A nivel doctrinal, se mantiene la división entre quienes consideran que existe una resistencia injustificada a la hora de articular la sujeción de la gestión económica desarrollada por los parlamentos a la misma fiscalización que realizan los órganos de control externo de la totalidad de las instituciones, administraciones, organismos y entidades que integran el sector público. Otros, sin embargo, siguen considerando que la ejecución autónoma del presupuesto y la no sujeción al principio de especialidad constituyen las piedras angulares de la autonomía administrativa: cualquier control externo sobre la ejecución del presupuesto parlamentario supone una injerencia que, a la postre, impediría preservar el principio de autonomía financiera.

Algunos sostienen que el control externo de la ejecución del presupuesto parlamentario por el Tribunal de Cuentas (en nuestro caso, por el Tribunal Vasco de Cuentas Públicas; en adelante TVCP) no implica injerencia alguna del Gobierno (tradicional enemigo de la autonomía parlamentaria), y que su existencia sería un ejemplo de trasparencia. Otros alegarán que, siendo el TVCP un órgano dependiente, y que ejerce sus funciones por delegación de la Cámara, sería contradictorio que pudiera fiscalizar la ejecución de su presupuesto. Más aún: podría llegar a considerarse que un informe del TVCP sobre la ejecución del presupuesto parlamentario que no encontrara tacha estaría viciado de origen, sería fruto de la pura sumisión, al haber sido nombrados los miembros del Tribunal por el sujeto controlado.

Cierto es que, como no podemos olvidar, independencia del Parlamento no equivale a impunidad que sustraiga a la Cámara del cumplimiento de la ley, ni que la autonomía parlamentaria pueda apartarse de su función instrumental como medio para garantizar la independencia de la institución representativa, sin constituir un fin en sí misma.

II.

Como dato adicional, habría que destacar que, en la finiquitada legislatura (XI), el Pleno del Parlamento tomó en consideración dos proposiciones de ley presentadas por los grupos parlamentarios Elkarrekin Podemos y Popular, posteriormente refundidas (Mesa de 11 de abril de 2017) en la iniciativa "De modificación de la ley 1/1988, de 5 de febrero, del Tribunal Vasco de Cuentas Públicas/Herri Kontuen Euskal Epaitegia”.

En la iniciativa, y en las enmiendas presentadas, se observa una evolución favorable al control, o fiscalización, de las cuentas del Parlamento por el TVCP, circunscrita a su actividad administrativa.

La proposición de ley tomada en consideración expresaba en su exposición de motivos, para justificar la extensión de las funciones de fiscalización del TVCP al Parlamento Vasco, que "La puesta de manifiesto de los posibles errores de funcionamiento del Parlamento no debe ser vista como un vehículo de 'escándalo de una democracia de especta- 
dores', sino que ha de considerarse como instrumento más de mejora y servir a la mayor calidad del funcionamiento de la más alta de nuestras instituciones".

En las enmiendas presentadas, cabe citar que tanto EH Bildu como el Grupo Popular no solo aceptaban la fiscalización de las cuentas del Parlamento, sino que la extendían a las juntas generales y a las diputaciones forales.

Por su parte, los grupos parlamentarios que sostenían al Gobierno (grupos Nacionalistas Vascos y Socialistas Vascos) expresaban, en una enmienda a la exposición de motivos de la proposición de ley, toda una declaración de intenciones, en el siguiente texto: “(...) por otro lado extender al Parlamento Vasco las funciones propias del Tribunal Vasco de Cuentas Públicas en su gestión administrativa, así como a los entes que de aquel dependen, unificando el criterio de sujeción del Sector Público Vasco y el Parlamento Vasco al control fiscalizador de las actividades económico-financieras y contables que desarrolla el Tribunal". Una enmienda al artículo 2 concretaba el alcance de esa declaración: "El Tribunal Vasco de Cuentas Publicas asistirá y fiscalizará al Parlamento en el control de la actividad económico-financiera vinculada a sus funciones estrictamente administrativas".

Con independencia de la redacción desafortunada de la enmienda, parece claro que lo que se pretendía introducir, como novedad en la ley, es que el TVCP, además de asistir al Parlamento en el control de su actividad económico-financiera, lo fiscalizara.

En definitiva, todos los grupos parlamentarios coincidían, con matices, en que el TVCP extienda sus funciones de fiscalización a la actividad del Parlamento Vasco, centrada en sus funciones administrativas, a falta de precisar cuáles son estas y si se pueden deslindar con precisión de otras que tienen naturaleza digamos política o parlamentaria en sentido estricto, pues al final habrá algunas de esas funciones que soportan el núcleo mismo de la independencia del Parlamento. Por ejemplo, el control de las subvenciones a los grupos parlamentarios y su destino o justificación, ¿es una función administrativa?

Parece que comienza a consolidarse un pensamiento común de que el principio de autonomía financiera del Parlamento Vasco está en revisión y que la aceptación de un control externo (externo en cuanto que la actividad funcional del TVCP no está mediatizada por el órgano de quien formalmente depende) gana terreno a través de la juridificación de otros principios como el de trasparencia.

Cabe señalar, sin embargo, que el intento de modificación de la Ley 1/1988, de 5 de febrero, del Tribunal Vasco de Cuentas Públicas/Herri Kontuen Euskal Epaitegia se quedó en eso, en una tentativa. Y que la ponencia que debía estudiar la proposición de ley y las enmiendas comenzó a reunirse en diciembre de 2019, justo cuando la legislatura estaba a punto de terminar. Al final, la iniciativa decayó con la disolución del Parlamento. 


\section{INFORME JURÍDICO SOBRE EL CONTROL EXTERNO DEL PRESUPUESTO PARLAMENTARIO}

\section{OBJETO}

En la sesión celebrada por la Comisión de Economía, Hacienda y Presupuestos el 27 de diciembre de 1995, se solicitó por unanimidad de los asistentes un informe jurídico relativo al control de la ejecución del presupuesto del Parlamento con especial atención a las fórmulas existentes en el derecho comparado.

Tras haber contrastado los mecanismos de control existentes en diversos Parlamentos de Europa, hemos considerado, dada la complejidad de la materia, ofrecer una perspectiva de análisis más amplia que la simple recopilación de las fórmulas que se vienen observando en otras latitudes. La cuestión objeto de informe afecta a elementos nucleares de la propia institución parlamentaria y una aproximación que no resulte superficial obliga a tener en cuenta perspectivas doctrinales, puntos de vista del derecho comparado, regulación legal vigente en Euskadi y una valoración crítica del conjunto.

\section{LA VERIFICACIÓN DEL PRESUPUESTO PARLAMENTARIO}

\section{A - LA CUESTIÓN EN LA DOCTRINA}

\section{Doctrina mayoritaria.}

La posición dominante entre los estudiosos de la materia se manifiesta a favor de la absoluta independencia de los Parlamentos en el control de sus presupuestos. La ausencia de control externo se encuentra enraizada con un principio axiomático, clásico, en el derecho parlamentario: la autonomía financiera de las Cámaras. En base a este principio de autonomía financiera se atribuye a los Parlamentos la suficiente y necesaria independencia frente a los demás poderes del Estado y, en particular, frente al Gobierno. Dicho en otras palabras, lo que persigue este principio es que las Cámaras puedan desarrollar sus funciones sin encontrarse mediatizadas por la carencia de fondos.

La autonomía financiera y contable de las Cámaras representativas tiene su origen histórico, político y jurídico en el principio de separación de poderes. Su formulación tuvo lugar en el momento mismo del nacimiento de los órganos representativos y estuvo acompañada de una larga lucha de éstos por afirmar su propia independencia de otros órganos y particularmente de la monarquía. Ya en la primera fase de la Revolución francesa, la Asamblea Nacional se dotó de su propia administración interna, independiente del poder ejecutivo que fue a abocar en diciembre de 1791 en el control exclusivo de su propio presupuesto. En el marco del proceso histórico que han vivido los Parlamentos, se ha venido afirmando gradualmente una total independencia y autonomía respecto a cualquier otra autoridad. Primero por la vía de hecho y después por el derecho, las Cámaras han reafirmado su administración propia, la inmunidad de sede, la policía interna, la autonomía presupuestaria, etc.

Aun cuando en nuestros días los principios de unidad y universalidad presupuestaria obligan a que las dotaciones correspondientes al Parlamento aparezcan formalmente englobadas en los Presupuestos Generales (del Estado, Comunidad Autónoma, etc.), su elaboración 
y aprobación compete en exclusiva al Parlamento. Las Cámaras no están sujetas al principio de especialidad presupuestaria en sentido cualitativo sino solamente en el cuantitativo, de tal forma que el órgano librador no puede pedir justificación alguna para la puesta a disposición del Parlamento de los fondos correspondientes. En otras palabras, los créditos para gastos de que pueden disponer los Parlamentos sólo han de estar limitados por la cuantía total de sus dotaciones, sin que les sea exigible por la ley de Presupuestos Generales que los destinen exclusivamente a finalidades o conceptos específicos. Otra cuestión distinta es, lógicamente, que el presupuesto parlamentario, a efectos internos, sí esté presidido por el principio de especialidad cualitativa y vincule a los órganos de la Cámara encargados de gestionar el gasto.

En resumen, la elaboración, aprobación y ejecución del presupuesto constituyen aspectos fundamentales de la autonomía financiera del Parlamento. Es indudable que la ejecución autónoma del presupuesto y la no sujeción al principio de especialidad constituyen las piedras angulares de la autonomía administrativa. Completando lo anterior, la doctrina mayoritaria excluye cualquier control externo sobre la ejecución del presupuesto parlamentario, precisamente para preservar el principio de autonomía financiera.

Citando un autor clásico, diríamos que el contenido de esta autonomía financiera de las Cámaras exige "que cada una de ellas tenga su propio presupuesto, preparado solo por ella, votado soberanamente y definitivamente liquidado por sí misma, sin ninguna injerencia del Ministerio de Finanzas ni del Tribunal de Cuentas" (Pierre).

Entre nosotros adquirió tempranamente aceptación el criterio sostenido por Fernando Santaolalla: los recursos económicos de las Cortes no están sometidos a ningún control externo, incluso al correspondiente al Tribunal de Cuentas, ya que al ser éste un órgano dependiente y que ejerce sus funciones por delegación de aquéllas (artículo 136-1 CE) sería contradictorio que pudiera fiscalizarlas.

\section{Posiciones críticas.}

Existen algunos autores que discrepan de las opiniones mayoritarias y defienden el control externo del presupuesto parlamentario por el Tribunal de Cuentas. Es evidente que estos autores no se manifiestan contrarios al principio de autonomía financiera de las Cámaras sino que consideran que el control externo de la ejecución de su presupuesto no menoscaba aquel principio. Según estos autores (Recoder, Gutiérrez Robles, Albiñana, etc.), el presupuesto parlamentario forma parte del sector público a los efectos de control externo por parte del Tribunal de Cuentas.

En líneas generales, se considera que la autoridad y prestigio de los Parlamentos saldría reforzada en la medida que potencien la transparencia en la actuación general, de la que forma parte importante la transparencia en la utilización de los fondos públicos que gestionan, máxime cuando, según se afirma, la gestión de los fondos públicos por los Parlamentos presenta una cierta opacidad que, en última instancia, redunda en desprestigio de la propia institución parlamentaria y del conjunto del sistema democrático.

Se indica igualmente que un control externo del presupuesto parlamentario, a través de la función fiscalizadora del Tribunal de Cuentas, no supone merma o menoscabo de la necesaria autonomía financiera del Parlamento puesto que éste sería en último término y sobre la base de los informes técnicos emitidos, el único competente para adoptar las medidas necesarias.

Por último, se aduce que la dependencia de los Tribunales de Cuentas de las Cámaras tampoco resulta un obstáculo substancial, toda vez que esta dependencia está dirigida a garantizar la actuación y funcionamiento de las instituciones de control frente al ejecutivo al que controlan y fiscalizan habitualmente, pero no supone interferencia en su gobierno, régimen interior, funcionamiento y programa de trabajo, campos en los que su autonomía queda plenamente garantizada por las leyes que las regulan. 


\begin{tabular}{|l|c|c|c|c|}
\multicolumn{1}{c|}{} & \multicolumn{2}{c}{ Tribunal de Cuentas } & Parlamento & ? \\
\cline { 2 - 5 } \multicolumn{1}{c|}{} & Estado & CC.AA. & $\checkmark$ & \\
\hline Andalucía & & & & \\
\hline Aragón & $\checkmark$ & & $\checkmark$ & \\
\hline Asturias & & & & \\
\hline Islas Baleares & & & & \\
\hline Canarias & & & & \\
\hline Cantabria & & & & \\
\hline Castilla-La Mancha & $\checkmark$ & & & \\
\hline Castilla y León & & & & \\
\hline Cataluña & & & & \\
\hline Extremadura & & & & \\
\hline Galicia & & & & \\
\hline Madrid & & & & \\
\hline Murcia & & & & \\
\hline Navarra & & & & \\
\hline La Rioja & & & & \\
\hline Valencia & & & & \\
\hline
\end{tabular}

\section{B - REGULACIONES EN EL DERECHO COMPARADO}

1. La verificación del presupuesto parlamentario en Europa.

En el Anexo $\mathrm{n}^{\mathrm{o}} 1$ adjuntamos un informe elaborado por la Secretaría General del Parlamento Europeo sobre la elaboración y control de los presupuestos parlamentarios. Dado que la documentación que se aporta ofrece un panorama exhaustivo del tratamiento de la cuestión abordada en este informe, nos limitaremos a reseñar los aspectos más relevantes.

Destacaríamos que en algunos países la ejecución del presupuesto parlamentario está sometida a la verificación o control de los órganos externos, tipo Tribunal de Cuentas. En Alemania, tanto el Bundestag como el
Bundesrat tienen su presupuesto controlado por el Tribunal de Cuentas; en Grecia, el presupuesto del Vouli ton Ellinon es controlado por el Tribunal de Cuentas; en Holanda, los presupuestos de las Cámaras están controlados por el Ministerio de Finanzas y el Tribunal de Cuentas; en Irlanda el Oireachtas por el Auditor General, y el presupuesto de la Cámara de los Lores y de los Comunes por la National Audit Office. En Bélgica se da la curiosidad de que el presupuesto del Senado es controlado por el Tribunal de Cuentas y sin embargo no lo es el de la Cámara de Representantes. En Dinamarca, España, Francia, Italia, Luxemburgo y Portugal son las propias Cámaras las que ejercen, a través de distintos mecanismos, el control de la ejecución de los presupuestos. 


\section{Sistemas adoptados por las CC.AA.}

A pesar de que, tal y como señalábamos, los presupuestos del Congreso y Senado (Cortes Generales) no están sometidos a control externo alguno y que es frecuente percibir el fenómeno de la emulación del sistema jurídico de las CC.AA. respecto al estatal, en la cuestión que nos ocupa no puede decirse que todos los Parlamentos autonómicos han seguido las pautas de las Cortes Generales. Como puede apreciarse en el cuadro siguiente, el presupuesto parlamentario es controlado en ocho CC.AA. (en nueve si contamos el País Vasco) por el propio Parlamento, en cuatro por el Tribunal de Cuentas del Estado y en tres por los Tribunales de Cuentas de la Comunidad respectiva. En el caso de Extremadura no hemos logrado concretar debidamente el sistema, por lo que dejaremos sin clasificar a esta Comunidad.

a) Parlamentos cuyo presupuesto es controlado por el Tribunal de Cuentas del Estado:

\section{a.1 - Aragón}

El control externo del presupuesto del Parlamento lo ejerce el Tribunal de Cuentas del Estado. Aparece recogido en el capítulo correspondiente del Informe que elabora el Tribunal de Cuentas sobre la Cuenta General de la Comunidad Autónoma de Aragón, correspondiente a los distintos ejercicios económicos.

\section{a.2 - Cantabria}

\section{Estatuto de Autonomía:}

Art. 7 Los poderes de la C.A. de Cantabria se ejercen a través de la Diputación Regional, la cual está integrada por la Asamblea Regional, el Consejo de Gobierno y el Presidente.

Art. 40 El control económico y presupuestario de la Diputación Regional se ejercerá por el Tribunal de Cuentas del Estado.
El informe del Tribunal de Cuentas será remitido, además de a las Cortes Generales, a la Asamblea Regional de Cantabria.

Lo establecido en los párrafos anteriores se llevará a cabo de acuerdo con lo que disponga la Ley Orgánica prevista en el artículo 136.4, de la Constitución.

\section{Reglamento de Gobierno y Régimen Interno:}

Art. 46 El control de la gestión económica de los órganos de la Asamblea se ejercerá:

a. Por la propia Asamblea, de acuerdo con los arts. 9 y 55 del Estatuto de Autonomía para Cantabria.

b. Por la Mesa de la Asamblea, en los términos previstos en el art. 32.I.2 ${ }^{\circ}$ del Reglamento de la Cámara.

c. Por la Intervención de la Cámara respecto al control interno, de acuerdo con lo dispuesto en este Reglamento.

\section{Reglamento de la Asamblea:}

Art. 32.1.2 ${ }^{\circ}$ Corresponde a la Mesa:

Elaborar el proyecto de presupuesto de la Asamblea, dirigir y controlar su ejecución y presentar ante el Pleno de la Cámara, al final de cada ejercicio, un informe acerca de su cumplimiento.

\section{a.3 - Castilla y León}

\section{Control externo:}

Ley $7 / 1986$, de 23 de diciembre de la Hacienda de la Comunidad de Castilla y León art. 8.4 "Las Cortes de Castilla y León estarán sometidas a sus propios órganos de control interno y justificarán su gestión directamente ante el Tribunal de Cuentas". 
En consecuencia el Tribunal de Cuentas del Estado está facultado para controlar la ejecución del presupuesto de las Cortes y a él se le remite directamente la liquidación del presupuesto de cada ejercicio, una vez que ha sido aprobado por la Mesa de la Cámara.

\section{Control interno:}

Reglamento de la Cámara art. $27 \cdot 1.2^{\circ}$ corresponde a la Mesa "elaborar el proyecto de presupuesto de las Cortes, dirigir y controlar la ejecución del presupuesto aprobado y presentar a la Cámara, al final de cada ejercicio, un informe acerca de su cumplimiento".

Este informe, una vez aprobado, se pone a disposición de los Procuradores y de los Grupos Parlamentarios y un extracto o resumen del mismo se publica en el Boletín Oficial de las Cortes.

\section{a.4 - Madrid}

El presupuesto de la Asamblea se incluye en la Cuenta General de la Comunidad para ser fiscalizado todo ello por el Tribunal de Cuentas del Estado, tal como se regula en la Ley /1990 [sic], de 8 de noviembre, reguladora de la Hacienda de la Comunidad de Madrid.

b) Parlamentos cuyo presupuesto es controlado por el Tribunal de Cuentas de su Comunidad

\section{b.1 - Castilla-La Mancha}

Ley 5/1993, de 27 de diciembre de 1993, de la Sindicatura de Cuentas.

Art. 8.1 A los efectos de esta Ley, componen el sector público de la Comunidad Autónoma de Castilla-La Mancha: a. Las Cortes Regionales, la Administración de la Junta de Comunidades de Castilla-La Mancha, sus Organismos Autónomos, Instituciones y Empresas.

Reglamento de organización y funcionamiento de la Sindicatura de Cuentas.

Disposición Transitoria $1^{\mathrm{a}}$ :

Las Corporaciones Locales, Cortes de Castilla-La Mancha y demás Entidades Públicas no territoriales sometidas a fiscalización, rendirán a la Sindicatura las Cuentas correspondientes al ejercicio 1994 y sucesivos, efectuándose la rendición de las correspondientes a ejercicios precedentes, conforme a la normativa vigente con anterioridad a la Ley $5 / 1993$.

\section{b.2 - Galicia}

El art. 76 del Reglamento de Régimen Interior del Consejo de cuentas de Galicia establece: "Las cuentas del Parlamento.

Sin perjuicio de lo dispuesto en la Ley de gestión económica y financiera pública de Galicia y en virtud de lo preceptuado en el artículo 4 de la Ley 6/1985, de 24 de junio, reguladora del Consejo de Cuentas, el Parlamento de Galicia remitirá a este Consejo, sus cuentas generales antes del 30 de julio del año siguiente al del ejercicio económico a que correspondan, para la fiscalización de las mismas."

\section{b.3 - Valencia}

Ley 6/1985, de 11 de mayo, de Sindicatura de Cuentas.

Art. 17. Corresponden al Consejo, como órgano supremo de la Sindicatura de cuentas, las siguientes funciones:

e. Emitir informe anual sobre la gestión económica del sector público valenciano y sus cuentas, e incluso de las propias Cortes Valencianas. 
Reglamento de Régimen Interior de la Sindicatura de Cuentas.

Art. 12: Corresponde al Consejo las siguientes funciones:

e. Emitir informe anual sobre la gestión económica del sector público valenciano y sus cuentas, e incluso de las propias Cortes Valencianas; y en su caso, en este sentido extenderá su actuación al ámbito de las entidades Locales que conforma el territorio de la Comunidad Autónoma en los términos previstos en el artículo 2 de la Ley de la Sindicatura de Cuentas.

c) Parlamentos cuyo presupuesto no está sometido a control externo

\section{c.1 - Andalucía}

Ley $9 / 1987$, de 9 de diciembre, de modificación de determinados artículos de la Ley 5/1983, de 19 de julio, de Hacienda de la Comunidad Autónoma de Andalucía:

Art. 3. El Parlamento de Andalucía goza de autonomía presupuestaria. Elabora y aprueba su Presupuesto y, en los términos que establezcan sus propias disposiciones, posee facultades plenas para la modificación, ejecución, liquidación y control del mismo.

En el primer mes de cada trimestre, la Consejería de Hacienda librará automáticamente y por cuartas partes las dotaciones presupuestarias del Parlamento de Andalucía.

\section{c.2 - Asturias}

La fiscalización del presupuesto de la Cámara se regula por el art. 36 del Reglamento de la Asamblea que establece la rendición de cuentas de la Mesa ante el Pleno cada año. c.3 - Canarias

Hay un interventor en la plantilla orgánica que realiza la función interventora. No existe control externo del presupuesto de la Cámara.

c.4 - Cataluña

No hay ningún control externo. El órgano competente es la Comisión de Gobierno Interior.

\section{Reglamento del Parlamento. Art. 46:}

1.- La Comisión de Gobierno Interior está formada por la Mesa del Parlamento más un Diputado en representación de cada Grupo Parlamentario, y adopta las decisiones por el sistema de voto ponderado.

2.- Le corresponden las siguientes funciones:

$1^{\text {o }}$. Elaborar los Estatutos de Régimen y Gobierno Interior de la Cámara.

$2^{\circ}$. Elaborar el presupuesto del Parlamento para su aprobación en Pleno.

$3^{\circ}$. Controlar la ejecución del presupuesto y presentar al Pleno la liquidación correspondiente en cada periodo de sesiones.

$4^{\circ}$. Aprobar la composición de las plantillas de personal del Parlamento y las normas que regulan su acceso.

$5^{\circ}$. Cumplir todas aquellas otras que le encomiende el presente Reglamento.

3.- Para el cumplimiento de la tarea referida en el punto tercero del apartado anterior, la Comisión de Gobierno Interior propondrá al Pleno la designación de tres Diputados interventores por cada periodo presupuestario, los cuales ejercerán la intervención material de todos los gastos y presentarán un informe cada dos meses de sus gestiones. 


\section{c.5 - Islas Baleares}

El Pleno aprueba la liquidación del presupuesto del Parlamento.

\section{c.6 - Murcia}

1.- No existe norma alguna específica del control del presupuesto parlamentario. Es aplicable la normativa general:

a. Art. 54 del Estatuto de Autonomía

b. Arts. 88-9I de la Ley de Hacienda de la Región de Murcia.

2.- El Reglamento de la Cámara (art. $42.4 .3^{\circ}$ ) indica que es competencia de la Comisión de Gobierno Interior "controlar su ejecución y rendir informe al Pleno, al término de su ejercicio, sobre su cumplimiento". El Estatuto de Régimen Interior y de Personal (art. 23) establece las mismas competencias.

\section{c.7 - Navarra}

Ley 8/1988, de 26 de diciembre, reguladora de la Hacienda de Navarra. (Artículos 113 y 114.1, y Disposición adicional $\left.1^{\mathrm{a}}\right)$

La Cámara de Comptos no ejerce el control sobre el presupuesto del Parlamento.

\section{c.8 - La Rioja}

El presupuesto de la Diputación Regional no tiene ningún control externo. El presupuesto se controla internamente mediante Diputados Interventores (art. 144 del Reglamento) que se reúnen trimestralmente a efectos de requerimiento de la ejecución del presupuesto y elaboran un informe anual sobre la misma que la Mesa de la Cámara eleva al Pleno para su aprobación.
Trimestralmente se envía al Consejo de Gobierno el informe de ejecución aprobado por los interventores para su conocimiento y apunte contable correspondiente.

Reglamento de la Diputación General. Art. 144: Para el mejor control de la ejecución del Presupuesto, se designarán tres Diputados Interventores, un por la mesa de entre sus miembros y dos por el Pleno, elegidos en la forma prevista por el artículo 4.2.c) de este Reglamento, que ejercerán la intervención material de todos los gastos y presentarán un informe de su gestión al final de cada ejercicio presupuestario.

\section{3 -Valoración crítica de los modelos.}

La primera cuestión que habría que señalar a la hora de realizar una valoración crítica de los sistemas vigentes en el derecho comparado es que la aparente sencillez de la clasificación no es sino un espejismo que no debe confundirnos a la hora de realizar translaciones automáticas de modelos.

Valorar el modelo vigente en un país implica un análisis de su arquitectura constitucional, de sus costumbres y evolución, de la naturaleza y funciones de los órganos controladores.

Pensemos en las distintas características que presentan los Tribunales de Cuentas del modelo latino en relación con el anglosajón. Tengamos en cuenta que los sistemas de nombramiento de los Tribunales de cuentas obedece a fórmulas diferentes, con y sin participación parlamentaria. Pensemos que en gran Bretaña la Oficina Nacional de Auditoría no tiene la estructura clásica que conforma a los Tribunales de Cuentas: no es un órgano colegiado, carece de funciones jurisdiccionales y su funcionamiento interno se aproxima, en cuanto a métodos y procedimientos de auditoría, al de una oficina especializada. Observemos que en los modelos europeos raramente se conjuga la dependencia del Tribunal de Cuentas del Parlamento con el ejerci- 
cio del control externo del presupuesto parlamentario. Fijémonos en la nota 2 del Anexo I de este informe: mientras que el Tribunal de Cuentas controla las cuentas del Senado belga, no verifica las de la Cámara de Representantes. La justificación aducida resulta sumamente significativa: el Tribunal de Cuentas es un órgano de la Cámara de Diputados y ello explica que no verifique las cuentas de la Cámara.

En lo que concierne a los sistemas seguidos por las CC.AA., hay que señalar que el origen de la normativa de aplicación resulta muy dispar. En algunos casos, el control que ejerce el Tribunal de Cuentas del Estado sobre el presupuesto parlamentario trae causa del Estado de Autonomía (Cantabria). En otros casos, el control externo del presupuesto parlamentario se establece en leyes autonómicas. Por último, cabe citar como curiosidad que en Galicia la obligación del control del presupuesto del Parlamento por el Consejo de cuentas de Galicia se establece no en la ley sino en el Reglamento de Régimen Interior del Consejo de cuentas de Galicia (art. 76), dándose la circunstancia de que este Reglamento fue aprobado por la Comisión competente del Parlamento.

Hay que indicar igualmente que en Italia la polémica sobre el control externo del presupuesto de los órganos constitucionales se suscitó a finales de los años setenta. También entonces un sector de la doctrina italiana propugnaba poner fin a lo que consideraba un privilegio anacrónico: la ausencia de control externo en el control del presupuesto de algunos órganos, entre ellos las Cámaras. El Tribunal de Cuentas, sin duda influenciado por aquellas propuestas doctrinales, adoptó una decisión sin precedentes en la historia constitucional italiana. Por Decreto de 30 de octubre de 1979 exigió al Tesorero del Senado la presentación de las cuentas relativas a los ejercicios 1969 y 1977. Idéntica intimidación fue efectuada a la Presidencia de la República y a la Corte Constitucional. Según la argumentación ofrecida por el Tribunal de Cuentas, también los presupuestos de los órganos constitucionales estaban obligados a ser controlados por un juez independiente e imparcial que en el ordenamiento italiano resultaba ser el Tribunal de Cuentas. El Tribunal de cuentas secundaba la doctrina que observaba el anacronismo de exonerar a los órganos constitucionales de rendir sus cuentas en la medida en que están también gestionando dinero público. Por otra parte, según manifestaba el Tribunal de Cuentas, el juicio contable no se extendía a la finalidad justificativa, a las decisiones adoptadas por los órganos gestores de la Asamblea legislativa (en este caso, decía, sí se podría hablar de minoración de la independencia de la Cámara), pero sí a valorar el comportamiento de los funcionarios que llevan el manejo del dinero público para determinar la regularidad de la gestión financiera.

Como consecuencia de la actuación del Tribunal de Cuentas, el Senado, la Cámara de los Diputados y la Presidencia de la República presentaron un recurso ante la Corte Constitucional por conflicto de atribuciones. La Cortes Constitucional, pro sentencia de 10 de junio de 1981, declaró que no compete al Tribunal de cuentas el poder someter a control las cuentas de la Presidencia de la República, de la Cámara y del Senado. Entre otras cosas, la sentencia determina que la autonomía administrativa y contable de las Cámaras es absoluta y no está sometida al control de parte de órganos o sujetos externos a las propias Cámaras. Esta sentencia trae causa de otra dictada en 1968 en la que la Corte Constitucional afirmaba que el control externo comprometía el libre ejercicio de la función políticolegislativa o de garantía constitucional atribuida a los órganos constitucionales.

Por último, cabe observar que el propio Parlamento Europeo ha seguido las pautas mayoritarias en el continente al establecer en su Reglamento (art. 166) el sistema de control interno de su presupuesto sin intervención alguna del Tribunal de Cuentas. 


\section{EL CONTROL DEL PRESUPUESTO PARLAMENTARIO VIGENTE EN EL PAIIS VASCO}

1. El art. 27 del Estatuto de Autonomía consagra el principio de autonomía financiera del Parlamento al disponer que aprobará su presupuesto y el Estatuto de su Personal.

El art. 23 del Parlamento atribuye a la Mesa la función de elaborar el proyecto de presupuesto de la Cámara, dirigir su ejecución y presentar ante el Pleno, al final de cada ejercicio, un informe acerca de su cumplimiento.

Por su parte, el art. 40 del Reglamento señala que corresponde a la Comisión de Urgencia Legislativa, Reglamento y Gobierno el estudio y aprobación del proyecto de presupuesto del Parlamento para su elevación al Pleno de la Cámara. Igualmente, esta Comisión es la competente para controlar la ejecución de los presupuestos y presentar al Pleno la liquidación correspondiente al final de cada ejercicio.

El art. 2 de la Ley 1/1988, de 5 de febrero, del Tribunal Vasco de Cuentas Públicas, excluye al Parlamento del ámbito de control del Tribunal, limitándose a señalar el punto 2 del referido artículo que "el Tribunal Vasco de Cuentas Públicas asistirá al Parlamento en el control de la actividad económico-financiera vinculada a sus funciones estrictamente administrativas".

Es evidente que de la regulación legal existente se desprende que el presupuesto del Parlamento Vasco no está sometido a control externo alguno. Es más, la Ley 1/1988 del Tribunal Vasco de Cuentas Públicas no hace sino ratificar este criterio en el citado art. 2 del que se deducen las siguientes conclusiones:

c. El Tribunal de Cuentas asiste al Parlamento, es decir, acompaña, socorre, favorece o ayuda.

d. Asiste al Parlamento en el control, esto es, sensu contrario, el control lo ejerce plenamente el Parlamento y la asistencia la presta el Tribunal. e. La asistencia del Tribunal se limita, en todo caso, a la actividad económico-financiera vinculada a sus funciones estrictamente administrativas. Se excluye, no ya el control, sino también la asistencia del Tribunal en aquellos ámbitos que constituyan manifestación de la autonomía organizativa y funcional del Parlamento.

En consecuencia, tanto el Reglamento de la Cámara como la propia ley de creación del Tribunal Vasco de Cuentas Públicas optaron por el modelo mayoritario vigente tanto en Europa como en el conjunto de las Comunidades autónomas. Y la decisión no se tomó sin conocimiento de causa. Las posiciones que propugnaban la consideración del presupuesto parlamentario como integrante del sector público a efectos de un control por el Tribunal de cuentas también fueron puestas entonces de relieve. Concretamente Eusko Alkartasuna propuso una enmienda en este sentido, aun cuando posteriormente la retirara para apoyar una transaccional que fue el origen del art. 2.2 de la ley del Tribunal Vasco de Cuentas Públicas.

2. A la hora de considerar fórmulas que garanticen la transparencia del presupuesto parlamentario hay que tener en cuenta circunstancias que le son peculiares y constituyen aspectos que no pueden quedar sin una mención especial.

En primer lugar hay que destacar que el presupuesto del parlamento es relativamente insignificante en comparación con el de la Comunidad Autónoma y su mayor parte es de gasto corriente. Además, su ejecución no se realiza por funcionarios u órganos unipersonales sino por la Mesa del Parlamento, cuya composición plural garantiza, en gran medida, la transparencia en la gestión del presupuesto.

3. El someter el presupuesto del Parlamento al control del Tribunal Vasco de Cuentas Públicas no solamente plantea problemas legales (la ley excluye el control) 
sino institucionales. Resulta difícil de explicar que un órgano estatutario como es el Parlamento pueda ser controlado por otro carente de relevancia estatutaria y que además ejerce sus funciones por delegación suya.

Es más que dudoso considerar que un control del Tribunal de cuentas sobre el presupuesto parlamentario incremente automáticamente el nivel de transparencia de la gestión de los fondos públicos encomendados al Parlamento. Si los informes de fiscalización no encontraran deficiencias o anomalías siempre cabría deducir que la especial posición del Tribunal de Cuentas en relación con el Parlamento ha tenido como consecuencia una intervención benevolente. Por el contrario, si el Tribunal informara sobre deficiencias en la gestión presupuestaria, desde los órganos del Parlamento podría interpretarse que las críticas estarían fundadas en el afán de demostrar la independencia.

Es bien cierto que lo expuesto no son sino meras conjeturas o elucubraciones sobre intenciones indemostrables. Sin embargo, resulta absolutamente indiscutible que la posición del Parlamento ante un eventual control de su presupuesto por el Tribunal de Cuentas es sumamente delicada. ¿Cómo cabría interpretar que el Parlamento rechazara o no aceptara las recomendaciones y críticas del Tribunal? Si aceptara las recomendaciones y críticas sin posibilidad de discrepancia, estaría mutilando su autonomía financiera. Si las rechazara estaría poniendo en entredicho y cuestionando la función de un órgano que ejerce las tareas fiscalizadoras por delegación suya.

Hay que entender que la ley del Tribunal Vasco de Cuentas Públicas, como decimos, tuvo en cuenta estas consideraciones y optó por la fórmula establecida en su art. 2.2. Sin embargo, la previsión legal no se ha desarrollado. El Parlamento tiene plena autonomía para establecer sistemas reforzados de control interno de su presupuesto, que garanticen la transparencia, contando con la asistencia del Tribunal de Cuentas. Las propuestas pueden ser diversas en este sentido, pero la fórmula establecida en el Parlamento de Cataluña nos parece que puede resultar plenamente satisfactoria para reforzar los sistemas internos de control y mejorar la transparencia en la gestión de los fondos públicos. La idea de designar Diputados-interventores, que pueden estar funcionalmente asistidos por personal del Tribunal de Cuentas, o parlamentarios que presenten un informe sobre la ejecución del presupuesto, asistidos en la misma forma, nos parece plenamente congruente con la legalidad y los principios que inspiran el sistema parlamentario.

\section{CONCLUSIONES}

La doctrina mayoritaria se manifiesta contraria al control externo del presupuesto parlamentario por considerarlo opuesto al principio de autonomía financiera del Parlamento.

Un criterio divergente, defendido de forma minoritaria, sostiene la compatibilidad de la autonomía financiera con el control externo del presupuesto parlamentario por los Tribunales de Cuentas.

En los modelos vigentes en Europa coexisten fórmulas diversas con predominio de la inexistencia de control externo sobre el presupuesto de las Cámaras. La trasposición de los sistemas de otros países no puede realizarse de forma automática sin considerar aspectos relativos a la arquitectura constitucional y a la naturaleza y funciones de los órganos controladores.

En lo que concierne a las CC.AA., en ocho Comunidades (nueve con el País Vasco) no existe control externo sobre el presupuesto parlamentario; en cuatro, el control lo ejerce el Tribunal de Cuentas del Estado; y en tres, el Tribunal de Cuentas de la respectiva Comunidad.

En Euskadi, el Estatuto y el resto del ordenamiento reconocen la autonomía financiera del Parlamento, excluyendo cualquier tipo de control externo sobre el presupuesto parlamentario.

La Ley 1/1988, de 5 de febrero, dispone en su artículo 2 que el Tribunal Vasco de Cuentas Públicas asisti- 
rá al Parlamento en el control de la actividad económico-financiera vinculada a sus funciones estrictamente administrativas. En otras palabras, el Parlamento ejerce plenamente el control de su presupuesto y esa tarea estará asistido (socorrido, ayudado) por el Tribunal Vasco de Cuentas Públicas.

El sistema legal vigente permite fórmulas de control interno reforzado del presupuesto parlamentario que no han sido desarrolladas. La idea de designar
Diputados-interventores asistidos funcionalmente por personal del Tribunal de Cuentas y que rindan su informe ante la Comisión competente o el Pleno resulta plenamente congruente con la legalidad y los principios que inspiran el sistema parlamentario.

Vitoria-Gasteiz, 12 de febrero de 1996 